\title{
PCI in High Risk Advanced Breast Cancer Patients
}

\author{
Haider Shukur ${ }^{1, *}$
}

\author{
${ }^{1}$ MD., MSc., Clinical Oncology, Najaf Cancer Clinic (NCC), Departments of Oncology, Faculty of Medicine ,Jaber Ibn Hayyan Medical \\ University \\ *Corresponding author. Email: shukurhaider@yahoo.com
}

\begin{abstract}
Background: A high incidence of brain metastases has been conveyed in patients with triple-negative and her 2-positive breast cancer receiving trastuzumab therapy. The rationale for prophylactic cranial irradiation is to regulate or eliminate unnoticeable micro-metastases without making unwanted harm. Methods: This prospective study investigated the role of prophylactic cranial irradiation for lowering the frequency of brain metastases for patients who had triple-negative and her2-positive advanced extra-cranial metastatic breast cancer including 48 succeeding patients, with this disease scenario were collected in this study \& were categorized into 2 arms over 3 years period: The first arm consisted of 24 patients who did not receive PCI. The second group included 24 patients who received PCI 25 Gray/10 fractions over 2 weeks carried 4 weeks after completion of chemotherapy with or without trastuzumab while hormone therapy is continuous for hormone-positive patients. All patients were primarily evaluated by brain CT scan with contrast or MRI which was part of the neurological assessment included before PCI then every 3 months in the first year, then every 6 months thereafter. Neuro-cognitive Functions (NCF) were estimated in both arms before and then 6 months and 1 year after PCI using Mini-Mental State Exam (MMSE). Health-related quality of life was assessed before and then 1 month and 3 months after PCI using Functional Assessment of Cancer Therapy-Brain (FACT-Br). Results, only four (16.6\%) patients developed symptomatic brain metastases in the treatment arm compared to nine (37.5\%) patients in the control arm, the median brain metastasis-free survival duration in the PCI arm was 22 months with a 95\% CI (18.37-25.62) compared with 16 months with a $95 \%$ CI (13.78-18.21) with $\mathrm{p}=0.011$, figure (1). A brain metastases hazard ratio $=$ $0.398,95 \%$ CI $(0.187 .0 .844)$ is significantly reduced by $60 \%$ in the PCI patients set when compared to no PCI arm at any given time over 30 months with p-value (0.016). All patients died due to progressive breast cancer. There were no death due to treatment. Three of the 24 patients experienced grade 3/4 toxicity (two grade 3 nausea and vomiting, one grade 4 nausea and vomiting). Grade 1 to 4 fatigue occurred in majority of the fifteen $(62.5 \%)$ treated patients, but only in $3(12.5 \%)$ grade 3 and 4 patients. Hair loss was virtually common as a consequence of chemotherapy, so no more alopecia was observed during PCI. Neurocognitive function in both groups was equal, without statistical differences between the MMSE scores between the two study arms ( $p=0.137)$. Most of the MMSE scores declined at a 6-month evaluation in the PCI group with a significant difference at a P value of 0.001 , but resumed to the baseline value in the one-year evaluation without statistical difference between the two arms, $\mathrm{P}=0.679$. The initial levels of evaluation of the quality of life of the respondents in both groups were comparable, without statistical differences, $\mathrm{P}=1.000$. In the PCI group, most of the scores (FACT-Br) were reduced at the 1-month evaluation compared to no PCI group with a significant difference at a $\mathrm{P}$ value of 0.050 , but returned almost to baseline at the 3 -month evaluation without statistical differences between the two groups, $(\mathrm{P}=0.162)$. Conclusions: PCI was linked with accepted toxicities \& give rise to lower frequency of brain secondary metastasis with prolonged median brain metastasis-free survival duration. Whether, this result may be interpreted into satisfactory therapeutic improvement necessite an additional assessment.
\end{abstract}

Keywords: Breast cancer, brain metastases, triple-negative, her2-positive, prophylactic cranial irradiation.

\section{INTRODUCTION}

Breast cancer is extreme common non-skin cancer in female, and its frequency continues to rise throughout the world [1].
Breast cancer survival has significantly enhanced \& the disease course has altered with aggressive multimodal therapies and the contribution of novel agents in latest years so that the number of longstanding breast cancer survivors similarly continues to increase with breast cancer patients comprising a great proportion of 
long-term cancer survivors. Breast cancer is a leading cause of brain metastases, generally second only to lung cancer, but in female patients it is the leading cause [2].

Despite the success in improving survival, the increasing rate of brain metastases as late complications has become a major clinical dilemma [3]. Although this cancer mostly metastasizes to bone, lung, \& liver and rarely metastasize to the brain, which is generally a delayed presentation of advanced breast cancer [4]. However, some reports suggest that the brain is the primary site of progression in a high proportion of patients with controlled systemic disease [5].

A mechanism that is usually proposed to explain this phenomenon is the selective destruction of nonbrain metastases by new chemotherapy regimens, which allows for the subsequent development of brain metastases. Breast cancer patients with brain metastases are generally younger than breast cancer patients with non-brain metastases [6]. The presence of brain metastases portends a poor fate off in breast cancer, with symptomatic disease indicating a worse quality of life \& increased morbidity and mortality [7].

Presently, median survival after a diagnosis of metastatic brain cancer changed widely, from 3 months to more than 2 years [8]. Up to one-third of patients with metastatic breast cancer will eventually develop brain metastases during the disease course [2].

The frequency of brain metastases in the breast cancer population continues to rise mainly due to improvements in systemic therapies leading to longerlasting control of extra-cranial metastatic disease and prolonged survival [9].

1. This increment in incidence probably due to:

2. Enhanced detection with advanced imaging modalities such as magnetic resonance imaging.

3. Prolonged survival of patients with excellent extracranial disease control with systemic therapies.

4. Restricted blood-brain permeability of systemic agents.

5. Biological sub-types such as triple-negative breast cancer \& her2-positive breast cancer with an increased propensity for brain metastases.

A numerous factor predicts an increased risk of brain metastases, including tumor of large size, tumor grade, younger age at diagnosis, number of positive axillary lymph nodes $(\geq \mathrm{N} 2)$, ER-negative tumor, short disease-free survival ( $<2$ years), triple-negative tumor subtype and her2 positive, furthermore BRCA1 phenotype and p53 abnormalities [10]. However, none of these factors reliably or consistently predict the risk of brain metastasis, and thus identifying significantly higher-risk subgroups of patients (who could become candidates for prophylactic cranial irradiation strategies) becomes difficult. A single factor of the above different factors that have appeared as a strong predictor of brain metastases in recent times is the phenotype of breast cancer, as triple-negative and her2positive tumor sub-types have been reported to have an incidence of $20-30 \%$ [11]

Her2-positive breast cancer has been reported to have a $25 \%$ to $35 \%$ incidence of brain metastases. Her2-negative breast cancer patients, on the other hand, have a lower frequency of brain metastases than her-2positie breast cancer patients [12]. The brain metastases incidence in breast cancer patient with her- 2 positive treated with trastuzumab is even more, alternating from $25 \%$ to $48 \%$ [13]. This may be possible due to the poor blood-brain barrier penetration of trastuzumab due to its high molecular weight $(\sim 148 \mathrm{kDa})$, it creates a tumor cell sanctuary. In addition, trastuzumab improves systemic control of extra-cranial disease and also increases survival, leading to the "unmasking" of brain metastases in patients who would otherwise have died of progression of systemic disease [14]. Therefore, the possibility of early diagnosis or prevention of brain metastases could lead to better survival and a better quality of life. The crucial key to an effective preventive central nervous system approach is the identification of high-risk patients based on images, clinicopathological factors, \& molecular profiles.

Several hypotheses have been proposed for the prophylaxis of brain metastases in this group of highrisk patients, such as:

1. Frequent detection with MRI screen. Early detection of occult brain metastases and treated with radiotherapy has also been revealed to decrease the incidence of brain death threefold (48\% versus $16 \%$ ) [15]. Although screening for brain metastases is not part of routine check-up, there is no proof evidence of advantage from early identification [16].

However, this may rather be due to the lack of satisfactory selection criteria for a potential screening cohort. Therefore, a more accurate definition of patients with breast cancer and sub-types at high risk of the early development of brain metastases is needed [17].

2. Use of substitute drugs for those patients' subtype with her2-positive cancer breast like lapatinib (with superior penetration of the blood-brain barrier). Treatment with lapatinib lead to decrease in the incidence rate of brain metastases in her2-positive disease [18].

3. Prophylactic cranial irradiation is usually used as an active and proven treatment to eradicate sub-clinical brain metastases, prevent symptomatic intracranial recurrence \& increase overall survival in various malignancies such as acute lymphoblastic leukemia \& small cell lung cancer [19]. 
Although breast cancer has been overly feared and underused as a treatment modality and not routinely used, as no survival benefit has been observed so far, it

\section{PATIENTS \& METHODS}

\subsection{Patient Eligibility}

This was a prospective study involving forty-eight patients with advanced breast cancer, who presented with triple-negative $(n=16)$ or her2-positive $(n=32)$ who had advanced extra-cranial metastatic disease confirmed by histology and radiology, as these patient groups were at high risk of developing brain metastases and then developing brain metastases during the followup period from February 2015 to January 2020 at Najaf Cancer Clinic (NCC) affiliate clinic, Jaber Ibn Hayyan Medical University was included in the study and randomized 24 patients to PCI and 24 patients to no PCI.

The procedures of staging included a full history \& physical examination, laboratory evaluations. Serum cancer antigen (CA15-3) \& carcinoembryonic antigen (CEA) levels were analyzed for pretreatment as a basis and a bilateral diagnostic mammogram when indicated, breast and abdomen-pelvis ultrasound, chest X-ray, and bone scintigraphy with radionuclides. Selected patients received computed tomography, positron emission computed tomography or magnetic resonance imaging of the breast as indicated.

At an interdisciplinary meeting of the Tumor Board is held where patients are presented \& discussed and made treatment guidelines recommendation rely on the National Comprehensive Cancer Network (NCCN).

Hormone-receptor, estrogen-receptor, \& progesterone receptor status were evaluated by immunohistochemistry (ERa antibody, clone 1D5, Dako A / S, Glostrup, Denmark; and PR antibody, Dako A / S). Receptor expression was estimated as the percentage of positively stained tumor cells. Results were reported as positive or negative spots 1,2 , and 3 with a $10 \%$ cutoff value of positive tumor cells [21].

Her-2 status was assessed via immunohistochemistry (Herceptest; Dako A / S) or dual-color fluorescent in situ hybridization (FISH; PathVision HER-2 DNA probe kit, Vysis Inc., Downers Grove, IL, USA). Tumors were classified as her2positive if they had a staining intensity of 3 on the Herceptest; if a score of 2 was obtained, the tumors were retested by FISH [22].

Systemic various chemotherapy options were administered to all patients depending on the characteristics of the patients. Tamoxifen with or without Zoladex or aromatase inhibitors has been used in hormone receptor-positive patients depend on their appears to be a realistic choice as there are no effective systemic therapies [20].

menopausal status. Trastuzumab was given to patients with her2-positive tumors.

Follow up on the periodic examination were programmed every twelve weeks for the first year, then every twenty-four weeks thereafter. PET-CT was requested during follow-up in many patients as indicated. Symptomatic secondary brain metastases were diagnosed via imaging (typically MRI or cranial computed tomography with contrast).

\section{Prophylactic cranial irradiation:}

Whole-brain irradiation was applied to $6 \mathrm{MV}$ LINAC (linear accelerator) and radiotherapy fields enclosed the whole brain with intracranial meninges, to comprise the cervical spine at the lower part of the first cervical vertebra using three-dimensional planned conformation radiotherapy (3-DCRT) providing 25 Gray in 10 fractions over 2 weeks, given the new data from pulmonary PCI studies.

PCI begins 4 weeks after completion of chemotherapy, while in her2-positive disease, continuing treatment with trastuzumab during PCI. Forty-eight breast cancer patients who attended at an advanced stage were evaluated every 3 months with CT or MRI of the head with contrast in the first year, then Thereafter, every 6 months, from February 2015 to January 2020 at the Najaf Cancer Clinic (NCC) affiliated clinic, Jaber Ibn Hayyan Medical University was eligible for inclusion.

\subsection{Inclusion criteria}

1. Woman with histologically proven breast cancer showing her2 positive 3+ on immunohistochemistry test or fluorescent in situ hybridization, or triple-negative disease;

2. Extra-cranial metastatic breast cancer;

3. WHO-PS of 0-2;

4. Adequate baseline organ function;

5. Age from 20 to 75 years;

6. A response after first-line chemotherapy;

7. Life expectancy longer than six months as assessed by the researcher;

8. Written informed consent was required.

\subsection{Exclusion criteria}

1. Over 75 years old.

2. Have had prior cranial irradiation or neurosurgery, or have had a history of cerebrovascular disease or neurological disorder, as well as seizures. Patients with identified or supposed brain or meningeal metastases (as defined by the presence of the crucial symptoms: headache, nausea and/or 
vomiting, clinical signs of elevated intracranial tension, seizures, focal neurological symptoms, cognitive dysfunction, affective disorder) ;

3. Pregnant or lactating women, female of childbearing potential unless they use effective contraceptive measures;

4. Severe dyspnea requiring supplemental oxygen therapy and uncontrolled severe systemic disease;

5. Patients with a simultaneous diagnosis of another none breast cancer;

6. Those with her2-positive and have not received first-line trastuzumab;

7. WHO-PS $\geq 3$;

8. Inadequate bone marrow.

\subsection{End Points}

- Primary endpoint was the time to development of symptomatic secondary brain metastases, measured as the interval from identification of the disease until the development of secondary brain metastasis. Diagnosis of symptomatic secondary brain metastases was completed via appropriate imaging (contrast-enhanced computed tomography or magnetic resonance imaging brain scan) triggered by clinical judgment based on the patient who developed one or more of the key symptoms, as defined above.

- Secondary endpoints were cerebral toxicity, NCF, \& QoL.

\subsection{Treatment evaluation included}

All patients were evaluated at the start of the study as a baseline and then every twelve weeks in the first year and then every twenty-four weeks thereafter, using high-resolution chest abdomen and pelvic computed tomography (HRCT) scan, chest X-ray, abdominal and pelvic ultrasound. Serum levels of cancer antigen (CA15-3) and carcinoembryonic (CEA) were analyzed at intervals during the evaluation of tumor response.

Physical examination and laboratory tests $(\mathrm{CBC}$ and biochemistry) were performed before treatment. Tumor response was classified into the complete response $(\mathrm{CR})$, partial response (PR), stable disease (SD), and progressive disease (PD) according to the criteria for estimating response in solid tumors (version 1.1) mentioned by Eisenhauer et at [23].

Adverse events were classified according to the NCI common terminology criteria for serious adverse events (version 4.0). The time between randomization \& occurrence of brain metastasis was defined as Brain metastasis-free survival (BMFS). Censored patients are those with no events on the last follow-up date (July 1, 2020). For patients with continuous information was collected at the time of follow-up visit.

\section{STATISTICAL ANALYSIS}

Analysis of statistics using an SPSS computer program (model 22). Numerical information was stated as median \& range as appropriate. Qualitative data were expressed as a percentage. Survival curves were estimated using the Kaplan-Meier technique.

\section{RESULTS}

Between February 2015 and January 2020, 48 patients who had established advanced breast cancer ( $\mathrm{TN}=16$, her2-positive $=32$ ) were enrolled in our clinic (NCC) at the Najaf Cancer Clinic (NCC) Affiliated Clinic, Jaber Ibn Hayyan Medical University, there were 24 patients randomized to receive PCI \& 24 randomized not to have treatment.

Closure of the study (from January 1, 2020) due to poor recruitment. The data displayed here were grounded on follow-up through 1 July 2020 with a median follow-up of 30 months (range 4 to 66 months). All patients received systemic chemotherapy and trastuzumab treatment as indicated, also hormone therapy as indicated in most patients. Baseline comparative patient characteristics for both arms were listed in Table 1.

The age group was between 22 and 67 years with an average age is 43.9 years in control arm while 44.3 years with a range of (21-70) in PCI arm of non-significant differences with a p-value of 0.728 , while two $(8.3 \%)$ were 65 years \& older compare to only one $(4.15 \%)$ in PCI arm. The majority of our patients $(66.6 \%$ in control arm versus $58.3 \%$ in treatment arm) were postmenopause with a non-significant difference with a $\mathrm{p}$ value of 1.00 . Also, the greatest percentage of our patients $(87.5 \%$ versus $87.4 \%)$ were of KPS of $0-1$ with a non-significant $\mathrm{p}$-value of 0.747 . More than two-thirds of our patients were diagnosed with ductal histology $(79.1 \%$ versus $70.8 \%)$ with a non -significant difference with a p-value of 0.096 . Majority of our patients $(79.1 \%$ vs $87.4 \%$ ) had tumor size of $2 \mathrm{~cm}$ and more and of nodepositive disease with a non-significant difference with a p-value of 0.162 and 0.622 for tumor size and positive node respectively. The maximum percentage of our patients $(91.6 \%$ vs $91.6 \%$ ) had grades 2 and 3 with a non-significant difference with a p-value of 0.479 . Twothirds of our patients $(66.6 \%$ her2-positive \& $33.3 \%$ triple-negative) with a non-significant difference in both groups with a p-value of 1.000. All patients in both groups had metastatic disease mostly to lungs were 41.6 $\%$ in control arm versus $37.5 \%$ in the treatment arm, but without significant difference with a p-value of 0.704 . 
Table-1: Comparative patients base-line characteristics

\begin{tabular}{|c|c|c|c|}
\hline Characteristic & $\begin{array}{c}\text { Control Arm } \\
\mathrm{N}=24\end{array}$ & $\begin{array}{c}\text { PCI Arm } \\
\mathrm{N}=24\end{array}$ & p-value \\
\hline $\begin{array}{l}\text { Age -Mean (Range ) } \\
\text { Age } \geq 65 \quad \text { No. }(\%)\end{array}$ & $\begin{array}{c}43.9(22-67) \\
2(8.3)\end{array}$ & $\begin{array}{c}44.2(21-70) \\
1(4.1)\end{array}$ & 0.728 \\
\hline $\begin{array}{l}\text { Menopausal Status-No.(\%) } \\
\text { Premenopausal } \\
\text { Postmenopausal }\end{array}$ & $\begin{array}{l}16(66.6) \\
8(33.3)\end{array}$ & $\begin{array}{l}14(58.3) \\
10(41.6)\end{array}$ & 1.00 \\
\hline $\begin{array}{l}\text { ECOG-PS-No.(\%) } \\
0 \\
1 \\
2\end{array}$ & $\begin{array}{l}12(50.0) \\
9(37.5) \\
3(12.5)\end{array}$ & $\begin{array}{c}11(45.8) \\
10(41.6) \\
3(12.5)\end{array}$ & 0.747 \\
\hline $\begin{array}{l}\text { BMI }(\mathrm{kg} / \mathrm{m} 2)-\text { No. }(\%) \\
<18 \\
18-25 \\
>25\end{array}$ & $\begin{array}{c}5(20.8) \\
13(54.1) \\
6(25.0)\end{array}$ & $\begin{array}{c}7(29.1) \\
13(54.1) \\
4(16.6)\end{array}$ & 0.103 \\
\hline $\begin{array}{l}\text { Histologic subtypes - No.(\%) } \\
\text { Ductal } \\
\text { Lobular } \\
\text { Other }\end{array}$ & $\begin{array}{c}19(79.1) \\
2(8.3) \\
3(12.5) \\
\end{array}$ & $\begin{array}{l}17(70.8) \\
3(12.5) \\
4(16.6) \\
\end{array}$ & 0.096 \\
\hline $\begin{array}{l}\text { Tumor size- No. }(\%) \\
\leq 2 \mathrm{~cm} \\
>2 \mathrm{~cm} \text { and } \leq 5 \mathrm{~cm} \\
>5 \mathrm{~cm} \\
\text { T4 tumor }\end{array}$ & $\begin{array}{l}5(20.8) \\
12(50.0) \\
3(12.5) \\
4(16.6)\end{array}$ & $\begin{array}{c}3(12.5) \\
10(41.6) \\
5(20.8) \\
6(25.0)\end{array}$ & 0.162 \\
\hline $\begin{array}{l}\text { Involvement lymph nodes-No. (\%) } \\
\text { N0 } \\
\text { N1-3 } \\
\text { N4-9 } \\
\text { N } \geq 10\end{array}$ & $\begin{array}{l}5(20.8) \\
6(25.0) \\
7(29.1) \\
6(25.0)\end{array}$ & $\begin{array}{l}3(12.5) \\
7(29.1) \\
8(33.3) \\
6(25.0)\end{array}$ & 0.622 \\
\hline $\begin{array}{l}\text { Histologic grade- No.(\%) } \\
\text { G1 } \\
\text { G2 } \\
\text { G3 }\end{array}$ & $\begin{array}{c}2(8.3) \\
8(33.3) \\
14(58.3)\end{array}$ & $\begin{array}{c}2(8.3) \\
11(45.8) \\
11(45.8)\end{array}$ & 0.479 \\
\hline $\begin{array}{l}\text { Ki-67 Status-No. }(\%) \\
\text { Low }(5 \%-15 \%) \\
\text { Intermediate }(16 \%-30 \%) \\
\text { High }(>30 \%)\end{array}$ & $\begin{array}{c}0(0.0) \\
11(45.8) \\
13(54.1)\end{array}$ & $\begin{array}{c}1(4.1) \\
9(37.5) \\
14(58.3)\end{array}$ & 1.000 \\
\hline $\begin{array}{l}\text { Hormone Status- No. }(\%) \\
\text { ER+/PR+ (double positive) } \\
\text { Single positive } \\
\text { ER-/PR- (double negative) }\end{array}$ & $\begin{array}{c}4(16.6) \\
5(20.8) \\
15(62.5) \\
\end{array}$ & $\begin{array}{c}5(20.8) \\
8(33.3) \\
11(45.8) \\
\end{array}$ & 0.347 \\
\hline $\begin{array}{l}\text { HER2 Status- No. }(\%) \\
\text { Positive } \\
\text { Negative }\end{array}$ & $\begin{array}{l}16(66.6) \\
8(33.3)\end{array}$ & $\begin{array}{l}16(66.6) \\
8(33.3)\end{array}$ & 1.000 \\
\hline $\begin{array}{l}\text { Luminal type-No. }(\%) \\
\text { Her2-positive } \\
\text { Her2-enrich } \\
\text { Triple Negative }\end{array}$ & $\begin{array}{l}12(50.0) \\
4(16.6) \\
8(33.3)\end{array}$ & $\begin{array}{c}13(54.1) \\
3(12.5) \\
8(33.3) \\
\end{array}$ & 0.491 \\
\hline $\begin{array}{ll}\text { Site of metastasis before initiation of PCI }- \text { No. }(\%) \\
\text { 1. } \\
\text { 2. } \\
\text { 3. Lone } \\
\text { Liver } \\
\text { Lung }\end{array}$ & $\begin{array}{c}7(29.1) \\
7(29.1) \\
10(41.6)\end{array}$ & $\begin{array}{l}8(33.3) \\
7(29.1) \\
9(37.5)\end{array}$ & 0.704 \\
\hline
\end{tabular}

Only one of 24 treated patients was discontinued for PCI after the first fraction of radiotherapy, due to grade 4 vomiting, was hospitalized due to circulatory collapse, and received parenteral nutrition and fluid replacement until hemodynamically stabilized and returned for the full course of radiotherapy after a week's delay. All these patients received the planned 25 Gray in 10 fractions within the 2 weeks included in the final analysis.

\subsection{Prophylactic Cranial Irradiation Effectiveness}

Only four patients developed symptomatic brain metastases in the treatment arm compared with nine patients in the control arm, and all those patients in both groups received therapeutic SRS with a change in systemic therapy. The median brain metastasis-free 
survival rate in the PCI arm was 22 months with a $95 \%$ CI (18.37-25.62) compared with 16 months with a $95 \%$ CI (13.78-18.21) with $\mathrm{p}=0.011$, figure (1). A hazard ratio of brain metastases $=0.398,95 \%$ CI $(0.187 .0 .844)$ is significantly reduced by $60 \%$ in the PCI arm compared to the non-PCI arm at any given time over 30 months with p-value equal to 0.016. Although all patients died of progressive breast cancer, but there was no treatment-related death.

\section{Survival Functions}

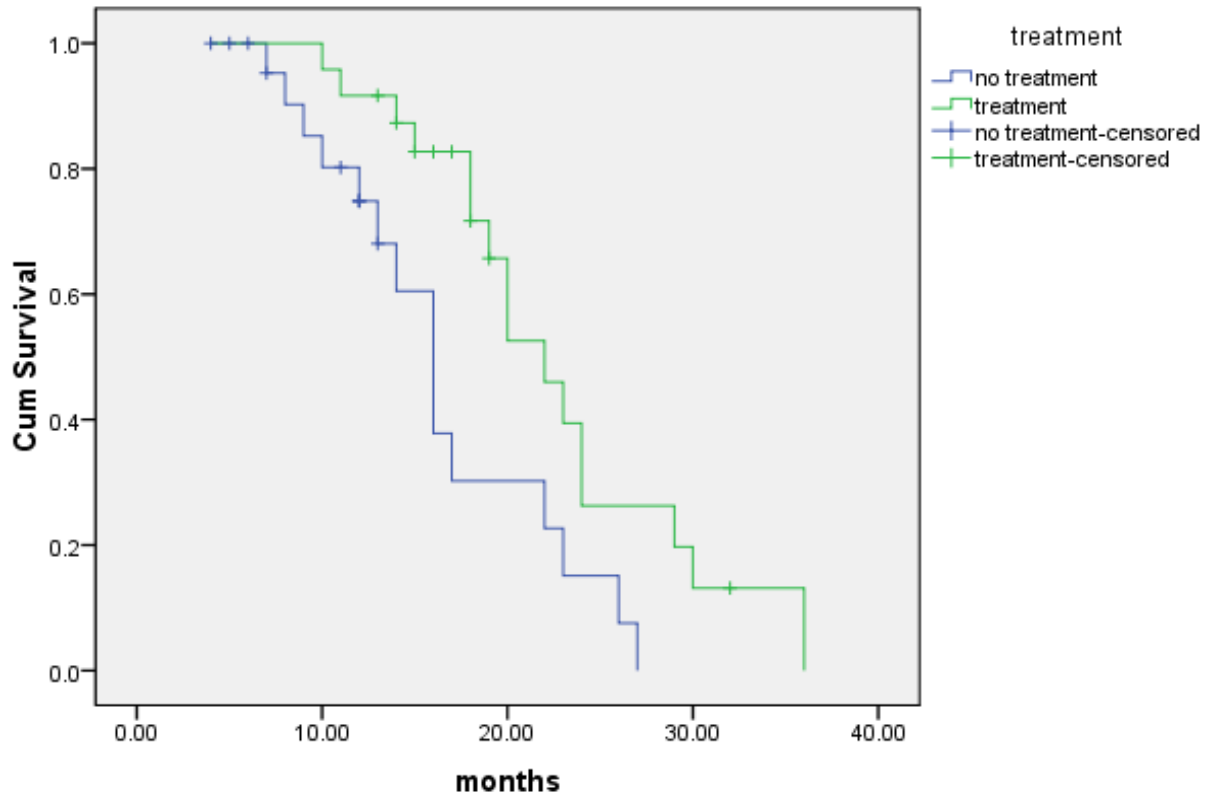

Figure 1. Kaplan-Meier curve of BMFS comparison

\subsection{Acute Toxicity of Prophylactic Cranial Irradiation}

The poorest perceived grade of every single adverse event throughout PCI treatment was documented using NCI CTCAE-v3. Three of the 24 treated patients experienced grade $3 / 4$ toxicity (two grade 3 nausea \& vomiting, one grade 4 nausea and vomiting).

Grade 1 to 4 fatigue occurred in most of the fifteen $(62.5 \%)$ treated patients, but only in $3(12.5 \%)$ grade 3 and 4 patients.

Hair loss was almost universal due to chemotherapy, so no excess alopecia was detected during PCI.

\subsection{Neurocognitive Function Impairment}

Neurocognitive Function Test: It is a way to measure brain function in a non-invasive way, basically we evaluate before \& then 6 months and 12 months after PCI by mean of the Mini-Mental State Exam (MMSE).

As we knew, breast cancer patients who received chemotherapy and combined endocrine therapies have been reported to show lower scores on a working memory task than patients who received chemotherapy or endocrine therapy alone [24].

Furthermore, a longitudinal study reported that treatment-induced menopause was associated with cognitive decline after chemotherapy in patients with early-stage breast cancer [25].

Patients receiving brain irradiation treatments often experience radiation-induced headache and fatigue, as well as possible cognitive decline. Whole-brain radiation therapy has been shown to worsen fatigue in cancer patients [26].

The European Organization for Research and Treatment of Cancer (EORTC) reported that patients who received whole-brain irradiation had a measurable cognitive decline that they attributed to fatigue, as well as clinically meaningful higher fatigue scores.

We assessed neurocognitive in both arms before \& then 6 months and 12 months after PCI by mean of the Mini-Mental State Exam (MMSE). The following four cut-off ranks were customized to categorize the severity of cognitive impairment: no cognitive impairment 2430; mild cognitive impairment 19-23; moderate cognitive impairment $10-18$; \& finally severe cognitive impairment $\leq 9$ as shown in Table 2 . 
Table-2: Comparative patients MMSE-Score results

\begin{tabular}{|l|c|c|c|c|c|c|c|}
\hline \multirow{2}{*}{ MMSE-Score } & \multicolumn{2}{|c|}{ Mild } & \multicolumn{2}{c|}{ Moderate } & \multicolumn{2}{c|}{ Severe } & P \\
\cline { 2 - 8 } & No PCI & PCI & No PCI & PCI & No PCI & PCI & 0.137 \\
\hline Base-line-No.(\%) & $12(50.0)$ & $7(29.1)$ & $5(20.8)$ & $9(37.5)$ & $7(29.1)$ & $8(33.3)$ & 0.001 \\
\hline 6-months-No.(\%) & $9(37.5)$ & $1(4.1)$ & $10(41.6)$ & $9(37.5)$ & $5(20.8)$ & $14(58.3)$ & 0.679 \\
\hline 1-year-No.(\%) & $7(29.1)$ & $7(29.1)$ & $13(54.1)$ & $11(45.8)$ & $4(16.6)$ & $6(25.0)$ & $0.67)$ \\
\hline
\end{tabular}

The preliminary assessment levels of neurocognitive function in both groups were identical, without statistical differences across MMSE scores between the two study arms, $\mathrm{P}=0.137$. In the PCI group, most MMSE scores declined at a 6-months assessment with a significant difference in a p-value of 0.001 but returned

\section{Correlation Parameters}

There is no correlation between BMFS in the PCI arm with age, menopausal status, KPS, abnormal BMI,

Table-3: Comparative patients QoL assessment results

\begin{tabular}{|l|c|c|c|c|c|c|c|c|c|}
\hline \multirow{2}{*}{ QoL-group } & \multicolumn{2}{|c|}{ Poor QoL } & \multicolumn{2}{c|}{ Fair QoL } & \multicolumn{2}{c|}{ Good QoL } & \multicolumn{2}{c|}{ Very good QoL } & P \\
\cline { 2 - 10 } & No PCI & PCI & No PCI & PCI & No PCI & PCI & No PCI & PCI & $11(45.8)$ \\
\hline Base-line-No.(\%) & $0(0)$ & $0(0)$ & $4(16.6)$ & $3(12.5)$ & $8(33.3)$ & $10(41.6)$ & $12(50.0)$ & 1.000 \\
\hline 1-month-No.(\%) & $3(12.5)$ & $5(20.8$ & $6(25.0)$ & $7(29.1)$ & $9(37.5)$ & $8(33.3)$ & $6(25.0)$ & $4(16.6)$ & 0.050 \\
\hline 3months-No.(\%) & $0(0)$ & $0(0)$ & $6(25.0)$ & $5(20.8)$ & $13(54.1)$ & $11(45.8)$ & $5(20.8)$ & $7(29.1)$ & 0.162 \\
\hline
\end{tabular}

to baseline at one-year assessment without statistical differences between both groups, $\mathrm{P}=0.679$.

\subsection{Quality of Life}

The respondents' initial quality of life assessment levels in both arms were identical, without statistical differences across the Functional Assessment of Cancer Therapy-Brain (FACT-Br) between the two study arms, $\mathrm{P}=1,000$. In the PCI group, most marks (FACT-Br) were lowered at the 1-month assessment compared to no PCI group with a significant difference in a p-value of 0.050 , but returned to near baseline on the 3 -month assessment with no difference statistics between the two groups, $\mathrm{P}=0.162$.
LN status, tumor size, her2-status, positive hormonal status, but there is a significantly negative correlation between BMFS \& disease grade, $(\mathrm{r}=-0.615)$ and $\mathrm{p}$ value 0.001 . Finally, there is a significant positive correlation between BMFS and quality of life at baseline, $(r=0.587) \& p$-value 0.003 , there is also a significant positive correlation at one month and at 3 months, $[(\mathrm{r}=0.483)$ and $\mathrm{p}=0.017],[(\mathrm{r}=0.401) \& \mathrm{p}-$ value 0.0501] respectively. There is no correlation between BMFS and the MMSE score. Identical detection in the control arm, as detailed in the table below.

Table 4: Correlation between BMFS in PCI arm with different variables

\begin{tabular}{|l|c|c|c|c|}
\hline \multirow{2}{*}{ Variables } & \multicolumn{2}{|c|}{ BMFS (PCI arm) } & \multicolumn{2}{c|}{ BMFS (No PCI arm) } \\
\cline { 2 - 5 } Age & $\mathbf{r}$ & $\mathbf{p}$ & $\mathbf{r}$ & $\mathbf{p}$ \\
\hline Menopause & -0.370 & 0.075 & -0.389 & 0.060 \\
\hline KPS & -0.321 & 0.126 & -0.373 & 0.073 \\
\hline Abnormal BMI & -0.335 & 0.109 & -0.299 & 0.156 \\
\hline Tumor size & -0.138 & 0.519 & -0.293 & 0.165 \\
\hline LN status & -0.053 & 0.806 & -0.108 & 0.615 \\
\hline Grade & -0.145 & 0.500 & -0.216 & 0.310 \\
\hline Positive Her2 & -0.615 & 0.001 & -0.063 & 0.771 \\
\hline Positive hormone & -0.054 & 0.801 & -0.172 & 0.422 \\
\hline QoL base-line & 0.311 & 0.139 & -0.445 & 0.029 \\
\hline QoL at 1 months & 0.587 & 0.003 & 0.616 & 0.001 \\
\hline QoL at 3 months & 0.483 & 0.017 & 0.408 & 0.048 \\
\hline MMSE Score base-line & 0.401 & 0.052 & 0.483 & 0.017 \\
\hline MMSE Score at 6 months & 0.169 & 0.429 & 0.568 & 0.004 \\
\hline MMSE Score at 1 year & 0.104 & 0.628 & 0.118 & 0.583 \\
\hline
\end{tabular}




\section{DISCUSSION}

In our prospective study, her2-positive and triplenegative advanced breast cancer patients with extracranial metastases had a $40 \%$ risk of emerging secondary brain metastases throughout the sequence of disease. For this of patients group, preventive medical intervention, such as prophylactic cranial irradiation treatment or diagnostic screening, may be helpful.

The best promising preventive medical interference to enhance outcomes may be prophylactic cranial irradiation. Postmortem revisions have revealed a high frequency of hidden brain metastases in patients with secondary metastatic breast cancer [27]. When brain metastases are diagnosed, survival is often short. Median survival rates reported for patients with breast cancer who have brain metastases generally range from 3 to 8 months [10].

Prophylactic cranial irradiation has been revealed to efficiently decrease the brain metastases frequency and improve lung cancer survival [28]. In a study of advanced-stage lung cancer (small cell type), prophylactic cranial irradiation lessen the frequency of brain metastasis from $40.4 \%$ to $14.6 \%$ ( $\mathrm{p}<0.001$ ) and enhanced the survival rate from $13.3 \%$. \% to $27.1 \%$ one year after stratification [29].

The whole radiation dose mandatory for effective prophylactic whole-brain irradiation is lower than that wanted for therapeutic whole-brain irradiation of symptomatic secondary brain metastases \& the corresponding toxicity is tolerable [30].

In our study, PCI led to an approximate numerical more than halving of the frequency of symptomatic secondary brain metastasis, via 30 months of follow-up, compared without PCI in the control group. The median brain metastasis-free survival was significantly different between PCI and no PCI arm [22 months with 95\% CI (18.37-25.62) versus 16 months with 95\% CI (13.78-18.21) with $\mathrm{p}=0.011$ ] respectively, which is negatively correlated with tumor grade, $\mathrm{p}=0.001$. The hazard ration of brain metastasis $=0.398,95 \%$ CI $(0.187,0.844)$ is significantly reduced by $60 \%$ in PCI arm compared to no PCI arm at any given time over 36 months period with $\mathrm{p}=0.016$.

The prophylactic cranial irradiation revealed a negative impact on verbal memory, however showed no or slight impact on overall cognitive function or overall health status compared to no prophylactic cranial irradiation [31]. Data are available from two prospective randomized studies of PCI versus no PCI in lung cancer (small cell type), which gauged toxicity and quality of life [32]. Both showed no deterioration owing to PCI during short-term follow-up, \& patients who had extended the survival duration more than 2 years after treatment showed no evidence of functional cognitive impairment or deterioration in quality of life [33].

Since a totally non similar patient population, the end results from these trials are therefore entirely unlike with our study, in which there was a discernible effect on cognitive function at 6 months follow-up post PCI, although at base-line evaluation levels of NCF in both groups were identical, without statistical difference through MMSE scores between both arms of the study, $\mathrm{P}=0.137$, however in PCI arm most of the MMSE scores were decreased at the 6 months assessment in PCI arm with significant $\mathrm{p}$-value difference 0.001 but returned to the original level at the 12 months assessment without statistical difference among both groups, $\mathrm{P}=0.679$.

On other hands, health-related quality of life initially prior to \& then 1 month and 3 months after PCI using Functional Assessment of Cancer Therapy-Brain (FACT-Br) which including 23 questioners and each item took one of four degrees ranging from zero to four, although, the base-line evaluation ranks of QoL questioners in both arms were identical, without statistical difference through Functional Assessment of Cancer Therapy-Brain (FACT-Br) between both groups of the study, p-value of 1.000. In PCI arm most of the (FACT-Br) degrees were declined at the 1 month's assessment compare to no PCI arm with significant pvalue difference 0.050 but resumed to near the initial level at the 3 months estimation without statistical difference among both groups, $\mathrm{P}=0.162$. Furthermore, three of 24 PCI-treated patients practiced grade $3 \& 4$ toxicity (two grade 3 nausea \& vomiting, one grade 4 ). Grade 1 to 4 fatigue had occurred in most fifteen $(62.5 \%)$ treated patients, but only $3(12.5 \%)$ patients of grades 3 and 4 . Hair loss was nearly universal due to chemotherapy therefore no excess was seen during the PCI.

Own to the lack of supporting data, PCI now shows no role in the treatment of breast cancer [20]. The time to development of brain metastases varies from patient to patient \& it can't be debarred that in selected patients seeding of tumor cells into the brain may happen later on next to whole-brain irradiation prophylactically. It is highly desirable that future randomized trials be conducted to assess the usefulness of prophylactic cranial irradiation in patients with high-risk breast cancer.

An additional hopeful prophylactic treatment for patients with the her2-positive disease could be lapatinib, a double tyrosine kinase inhibitor of EGFR \& HER2. Fewer cases with secondary brain metastasis were observed in early progression after lapatinib treatment in a preliminary analysis of a randomized breast cancer trial ( 4 vs 13 , the total number of patients 399; $\mathrm{P}=0.045$ ) [34]. Lapatinib with Xeloda has also displayed a good job as a first-line treatment of 
secondary brain metastases from her2-positive cancer breast in a phase II study [35].

The worth of brain metastases diagnostic screening in breast cancer patients is unclear. Patients with single brain metastases appear to have wonderful survival than those with multiple metastases [36], \& with surgery and stereotactic radiotherapy, there are effective treatment choices for patients with limited number of brain metastasis 1-5 that is called (oligo brain metastasis). Though, early recognition of secondary brain metastases has not until now been shown to expand survival [37]. In this study, the adversarial prognostic features intended for brain metastasis-free survival in the univariate analysis are tumor grade, other factors were unrelated.

The restrictions of our study are linked to the small sample size. The observed nonexistence of a statistically significant impact of early age at diagnosis, advanced disease and other factors on secondary brain metastasis-free survival may be possibly explained by insufficient statistical power of our study.

\section{CONCLUSION}

Patients with her2-positive and triple-negative advanced breast cancer with extra-cranial metastases had a nearly $40 \%$ risk of developing brain metastases during course of the disease. Although there was an excess of tolerated toxicity in the PCI received patients compared to the non-PCI arm regarding cognitive function or quality of life, both returned to baseline after some time. All deaths in the PCI group owing to progressive breast cancer and no treatment-related deaths. PCI has resulted in a numerical halving of the frequency of symptomatic secondary brain metastases, which is statistically significant.

\section{REFERENCES}

[1] Bray F, Ferlay J, Soerjomataram I, Siegel RL, Torre LA, Jemal A. Global cancer statistics 2018: GLOBOCAN estimates of incidence and mortality worldwide for 36 cancers in 185 countries. CA Cancer J Clin. 2018; 68:394-424.

[2] Fox BD, Cheung VJ, Patel AJ, Suki D, Rao G. Epidemiology of metastatic brain tumors. Neurosurg Clin N Am. 2011; 22:1-6.

[3] Pestalozzi BC, Zahrieh D, Price KN, Holmberg SB, Lindtner J, Collins J,Crivellari D, Fey MF, Murray E, Pagani O, Simoncini E, Castiglione-Gertsch M, Gelber RD, Coates AS, Goldhirsch A (2006) Identifying breast cancer patients at risk for Central Nervous System (CNS) metastases in trials of the
Forthcoming prospective trials are highly desirable to assess the effectiveness of a preventive medical intervention, such as prophylactic treatment or diagnostic screening for these high-risk patients.

\author{
ABBREVIATION \\ 3-DCRT : three-dimensional planned conformation \\ radiotherapy \\ ESMO: The European Society for Medical Oncology \\ HER2: Human epidermal growth factor receptor 2 \\ Gy :gray \\ FACT-Br: Functional Assessment of Cancer Therapy- \\ Brain \\ QoL: Quality of life \\ LINAC : linear accelerator \\ MBC: Metastatic breast cancer \\ MMSE: Mini-Mental State Exam \\ NCF: Neuro-cognitive Functions \\ PCI : prophylactic cranial irradiation \\ WHO-PS: World Health. Organization Performance \\ Status.
}

ACKNOWLEDGMENTS: I would like to thank my Colleague Assistant professor Thaer Wally for his assistance with information collection and statistical calculations also thanks for other sub-staff for considerable aid and patient support and finally thanks for our patients accepted to treatment and remained in close follow up.

Conflict of Interest: There is absolutely no potential conflict of interest, nor any beneficial relation with drug company.

Ethical Clearance: Taken from our scientific university committee (Jaber Bin Hayyan Medical University)

International Breast Cancer Study Group (IBCSG). Ann Oncol 17(6): 935-944

[4] DiStefano A, Yong Yap Y, Hortobagyi GN et al (1979) The natural history of breast cancer patients with brain metastases. Cancer 44:1913-1918. doi:10.1002/1097-0142(197911)44:5 1913::AIDCNCR2820440554[3.0.CO;2-D

[5] Clayton AJ, Danson S, Jolly S et al (2004) Incidence of cerebral metastases in patients treated with trastuzumab for metastatic breast cancer. $\mathrm{Br} \mathrm{J}$ Cancer 91:639-643

[6] Gnerlich JL, Deshpande AD, Jeffe DB, Sweet A, White N, Margenthaler JA. Elevated breast cancer mortality in women younger than age 40 years compared with older women is attributed to poorer 
survival in early-stage disease. J Am Coll Surg. 2009; 208:341-7.

[7] Ogawa K, Yoshii Y, Nishimaki T, et al. Treatment and prognosis of brain metastases from breast cancer. J Neurooncol 2008; 86:231-238.

[8] Sperduto PW, Kased N, Roberge D, et al. Efect of tumor subtype on survival and the graded prognostic assessment for patients with breast cancer and brain metastases. Int J Radiat Oncol Biol Phys. 2012; 82:2111-7.

[9] Lin X, DeAngelis LM. Treatment of brain metastases. J Clin Oncol. 2015; 33:3475-84.

[10] Berghoff A, Bago-Horvath Z, De Vries C, Dubsky P, Pluschnig U, Rudas M, Rottenfusser A, Knauer M, Eiter H, Fitzal F, Dieckmann K, Mader RM, Gnant M, Zielinski CC, Steger GG, Preusser M, Bartsch R: Brain metastases free survival differs between breast cancer subtypes. Br J Cancer 2012, 106(3):440-446.

[11] Foulkes WD, Smith IE, Reis-Filho JS. Triplenegative breast cancer. N Engl J Med 2010; 363:1938-48.

[12] Gori S, Rimondini S, De Angelis V, Colozza M, Bisagni G, Moretti G, et al. Central nervous system metastases in HER2 positive metastatic breast cancer patients treated with trastuzumab: Incidence, survival, and risk factors. Oncologist 2007; 12:76673.

[13] Duchnowska R, Szczylik C. Central nervous system metastases in breast cancer patients administered trastuzumab. Cancer Treat Rev 2005; 31:312-8.

[14] Sanna G, Franceschelli L, Rotmensz N, Botteri E, Adamoli L, Marenghi C, Munzone E, Cossu Rocca M, Verri E, Minchella I, Medici M, Catania C, Magni E, Goldhirsch A, Nole F (2007) Brain metastases in patients with advanced breast cancer. Anticancer Res 27(4C): 2865-2869

[15] Niwinska A, Tacikowska M, Murawska M. The effect of early detection of occult brain metastases in HER2-positive breast cancer patients on survival and cause of death. Int J Radiat Oncol Biol Phys 2010; 77:1134-9.

[16] Niwinska A, Tacikowska M, Pienkowski T (2007) Occult brain metastases in HER2-positive breast cancer patients: frequency and response to radiotherapy. Acta Oncol 46(7): 1027-1029

[17] Heitz F, Harter P, Lueck HJ, Fissler-Eckhoff A, Lorenz-Salehi F, Scheil-Bertram S, Traut A, du Bois A (2009) Triple-negative and HER2overexpressing breast cancers exhibit an elevated risk and an earlier occurrence of cerebral metastases. Eur J Cancer 45(16): 2792-2798

[18] Geyer CE, Forster J, Lindquist D, Chan S, Romieu CG, Pienkowski T, Jagiello-Gruszfeld A, Crown J, Chan A, Kaufman B, Skarlos D, Campone M, Davidson N, Berger M, Oliva C, Rubin SD, Stein S, Cameron D (2006) Lapatinib plus capecitabine for HER2-positive advanced breast cancer. N Engl J Med 355(26): 2733-2743

[19] Yazici O, Ozdemir NY, Sendur MA, Aksoy S, Zengin N. Current approaches for prophylactic cranial irradiation in extrapulmonary small cell carcinoma. Curr Med Res Opin 2014; 30:1327-36.

[20] Saip P, Cicin I, Eralp Y, Karagol H, Kucucuk S, Cosar Alas R, Yavuz E, Dincer M, Saglam E, Topuz E (2009) Identification of patients who may benefit from the prophylactic cranial radiotherapy among breast cancer patients with brain metastasis. J Neurooncol 93(2): 243-251.

[21] Hammond ME, Hayes DF, Dowsett M, Allred DC, Hagerty KL, Badve S, Fitzgibbons PL, Francis G, Goldstein NS, Hayes M, Hicks DG, Lester S, Love R, Mangu PB, McShane L, Miller K, Osborne CK, Paik S, Perlmutter J, Rhodes A, Sasano H, Schwartz JN, Sweep FC, Taube S, Torlakovic EE, Valenstein $\mathrm{P}$, Viale G, Visscher D, Wheeler T, Williams RB, Wittliff JL, Wolff AC (2010) American Society of Clinical Oncology/College Of American Pathologists guideline recommendations for immunohistochemical testing of estrogen and progesterone receptors in breast cancer. J Clin Oncol 28(16): 2784-2795

[22] Wolff AC, Hammond ME, Schwartz JN, Hagerty KL, Allred DC, Cote RJ, Dowsett M, Fitzgibbons PL, Hanna WM, Langer A, McShane LM, Paik S, Pegram MD, Perez EA, Press MF, Rhodes A, Sturgeon C, Taube SE, Tubbs R, Vance GH, van de Vijver M, Wheeler TM, Hayes DF (2007) American Society of Clinical Oncology/College of American Pathologists guideline recommendations for human epidermal growth factor receptor 2 testing in breast cancer. J Clin Oncol 25(1): 118 145

[23] Witzel I, Muller V, Abenhardt W, et al. Long-term tumor remission under trastuzumab treatment for her2 positive metastatic breast cancer - results from the her-os patient registry. BMC Cancer 2014; 14:806.

[24] Rodgers J, Morse R, Verrill M, et al. Cognitive functioning in women following adjuvant treatment for breast cancer. J Psychopharmacol. 2003;17: A68. 
[25] Jenkins V, Shilling V, Deutsch G, et al. A 3-year prospective study of the effects of adjuvant treatments on cognition in women with early-stage breast cancer. Br J Cancer. 2006; 94:828-834.

[26] Soffietti R, Kocher M, Abacioglu UM, et al. A European Organisation for Research and Treatment of Cancer phase III trial of adjuvant whole-brain radiotherapy versus observation in patients with one to three brain metastases from solid tumors after surgical resection or radiosurgery: quality-of-life results. J Clin Oncol. 2013; 31:65-72.

[27] Tsukada Y, Fouad A, Pickren JW, Lane WW: Central nervous system metastasis from breast carcinoma. Autopsy study Cancer 1983, 52(12):2349-2354.

[28] Blanchard P, Le Pechoux C: Prophylactic cranial irradiation in lung cancer. Curr Opin Oncol 2010, 22(2):94-101.

[29] Slotman B, Faivre-Finn C, Kramer G, Rankin E, Snee M, Hatton M, Postmus P,Collette L, Musat E, Senan S: Prophylactic cranial irradiation in extensive small-cell lung cancer. $\mathrm{N}$ Engl $\mathrm{J}$ Med 2007, 357(7):664-672.

[30] Le Pechoux C, Dunant A, Senan S, Wolfson A, Quoix E, Faivre-Finn C, Ciuleanu T, Arriagada R, Jones R, Wanders R, Lerouge D, Laplanche A: Standard-dose versus higher-dose prophylactic cranial irradiation (PCI) in patients with limitedstage small-cell lung cancer in complete remission after chemotherapy and thoracic radiotherapy (PCI 99-01, EORTC 22003-08004, RTOG 0212, and IFCT 99-01): a randomised clinical trial. Lancet Oncol 2009, 10(5):467-474.

[31] Welzel G, Fleckenstein K, Schaefer J, Hermann B, Kraus-Tiefenbacher U, Mai SK,Wenz F: Memory function before and after whole brain radiotherapy in patients with and without brain metastases. Int $\mathbf{J}$ Radiat Oncol Biol Phys 2008,72(5):1311-1318.

[32] Arriagada R, Lechevalier T, Borie F, et al. Prophylactic cranial irradiation for patients with small-cell lung-cancer in complete remission. J Natl Cancer Inst 1995;87(3): 183e190.

[33] Gregor A, Cull A, Stephens RJ, et al. Prophylactic cranial irradiation is indicated following complete response to induction therapy in small cell lung cancer: results of a multicentre randomised trial. Eur J Cancer 1997;33(11):1752e1758.

[34] Cameron D, Casey M, Press M, Lindquist D, Pienkowski T, Romieu CG, Chan S, JagielloGruszfeld A, Kaufman B, Crown J, Chan A, Campone M, Viens P, Davidson N, Gorbounova V, Raats JI, Skarlos D, Newstat B, Roychowdhury D, Paoletti P, Oliva C, Rubin S, Stein S, Geyer CE: A phase III randomized comparison of lapatinib plus capecitabine versus capecitabine alone in women with advanced breast cancer that has progressed on trastuzumab:updated efficacy and biomarker analyses. Breast Cancer Res Treat 2008,112(3):533-543.

[35] Bachelot T, Romieu G, Campone M, Dieras V, Cropet C, Dalenc F, Jimenez M, Le Rhun E, Pierga JY, Goncalves A, Leheurteur M, Domont J, Gutierrez M, Cure H, Ferrero JM, Labbe-Devilliers C: Lapatinib plus capecitabine in patients with previously untreated brain metastases from HER2positive metastatic breast cancer (LANDSCAPE): a single-group phase 2 study.Lancet Oncol 2013, 14(1):64-71.

[36] Harputluoglu H, Dizdar O, Aksoy S, Kilickap S, Dede DS, Ozisik Y, Guler N, Barista I, Gullu I, Hayran M, Selek U, Cengiz M, Zorlu F, Tekuzman G,Altundag K: Characteristics of breast cancer patients with central nervous system metastases: a single-center experience. J Natl Med Assoc 2008, 100(5):521-526.

[37] Tomasevic ZI, Rakocevic Z, Tomasevic ZM, Milovanovic Z, Inic M, Kolarevic D, Lukic V, Kovac Z: Incidence of brain metastases in early stage HER2 3+ breast cancer patients; is there a role for brain $\mathrm{CT}$ in asymptomatic patients? J BUON: official j Balkan Union of Oncol 2012, 17(2):249253. 